\title{
THE RELATIONSHIP BETWEEN STOCK RETURN SKEWNESS AND BANK FEATURES
}

\author{
SILVIA BRESSAN* and ALEX WEISSENSTEINER ${ }^{\dagger}$ \\ Free University of Bozen, Bolzano, Italy \\ *silvia.bressan@unibz.it \\ †alex.weissensteiner@unibz.it
}

Received 20 February 2018

Accepted 24 October 2018

Published 7 December 2018

\begin{abstract}
This paper studies to what extent bank-specific characteristics relate to stock return skewness. The main finding is that stock return skewness decreases significantly in bank size, measured in terms of total assets, i.e stocks of large banks are less skewed than those of small banks. This result holds for backward-looking skewness computed using the past stock returns, as well as for forward-looking skewness extracted from stock options. We interpret the empirical evidence by arguing that bank size increases the likelihood to have severe losses, to the point that investors expect to be compensated by receiving higher expected returns.
\end{abstract}

Keywords: Banks; expected returns; skewness.

JEL Classification: G21, G32

\section{Introduction and Connection to the Literature}

Skewness of stock returns has been studied quite extensively in the literature. For example, some papers attempt to interpret the stylized fact that aggregate stock market returns display negative skewness. Black (1976) and Christie (1982) claim that this pattern is due to the increasing leverage of firms. Campbell \& Hentschel (1992) gives an explanation in terms of the so-called "volatility feedback" emphasized by Pindyck et al. (1984) and French et al. (1987).

Also stock market practices have been identified to explain the aggregate skewness. For instance, Diamond \& Verrecchia (1987) examine the implications of short selling constraints, while Ekholm \& Pasternack (2005) and Epstein \& Schneider (2008) document that disclosure policies and information quality imply changes of

This is an Open Access article published by World Scientific Publishing Company. It is distributed under the terms of the Creative Commons Attribution 4.0 (CC-BY) License. Further distribution of this work is permitted, provided the original work is properly cited. 
skewness. Finally, Hong \& Stein (2003), Chen et al. (2001) and Xu (2007) relate stock return skewness to trading volumes.

A stream of research attempts to establish the link of firm-specific skewness to future expected returns. The seminal papers in this field are Arditti (1967) and Scott \& Horvath (1980), while more recently Brunnermeier \& Parker (2005), Brunnermeier et al. (2007) and Barberis \& Huang (2008) provide a theoretical framework justifying the statement that negative stock return skewness implies high expected returns. The argument is that, ceteris paribus, investors have a preference for stocks with positive skewness, as right-tailed stock returns imply a higher probability of benefiting from huge gains than suffering under huge losses. When skewness turns negative instead, the firm has a higher risk to perform badly. Consequently, investors demand higher expected returns, i.e. a risk premium, for left-skewed stocks. Following this line of reasoning, empirical research has analyzed the correlation between ex-ante skewness and ex-post returns. For example, Mitton \& Vorkink (2007), Boyer et al. (2010), Bali \& Murray (2013) and Conrad et al. (2013) document that ex-post returns move in the opposite direction to ex-ante skewness, thereby confirming the argument outlined above. Different methodologies have been proposed in the literature to measure stock return skewness. For example, Mitton \& Vorkink (2007) and Boyer et al. (2010) measure skewness based on the past stock returns. Instead, Bali \& Murray (2013) and Conrad et al. (2013) use stock options to extract options-implied moments, which according to Chang et al. (2013) and Conrad et al. (2013) would provide a more precise forecast of the future returns. ${ }^{\text {a }}$

The previous literature provides evidence for the skewness of nonfinancial firms, in reflection of the diffuse practice among empiricists to analyze separately financial firms from nonfinancial firms. To the best of our knowledge, there is no other paper that looks at the stock return skewness of banks. Therefore, this paper attempts to fill the gap of examining bank skewness in relation to bank-specific features.

Using a sample of financial institutions from the United States, our main finding is that skewness decreases significantly with bank size, measured in terms of bank total assets. The impact of other characteristics, as for example capital ratios, profitability, or growth options, is much weaker in statistical terms. This outcome is robust for backward-looking skewness computed using past stock returns (Mitton \& Vorkink 2007, 2010, Boyer et al. 2010 and Del Viva et al. 2017), as well as for forward-looking skewness calculated with stock options (Malz 2014). Additional evidence for systemically important financial institutions (SIFIs) confirms that systemic importance diminishes skewness.

\footnotetext{
a The empirical evidence though remains mixed, and the correlation between skewness and stock returns is positive in the papers of Stilger et al. (2016) and Bali et al. (2017). Jia \& Yan (2016) develop a model where the skewness of firm fundamentals predicts differences across stock returns. In this paper, we look only at stock return skewness, while not at the skewness in the distribution of other corporate fundamentals.
} 
Our results suggest a strong link between bank size and skewness. Large banks have long left-tailed stock returns. Relying on the above hypothesis that firm-specific skewness is informative on expected stock returns, we conclude that bank size is an important element for the assessment made by investors on the future bank returns and consequently on bank valuation.

The paper proceeds as follows. Section 2 introduces the sample and the main variables for the analysis. Section 3 tests the empirical relationship between skewness and bank-specific features. Section 4 examines the skewness of SIFIs. Section 5 concludes.

\section{Sample and Methodology}

\subsection{The sample}

We source the data for the analysis from Orbis Bank Focus and from Datastream. We focus on companies from the United States classified by Orbis Bank Focus as "financial firms." We keep only the firms "listed" and "active," obtaining the annual accounting-based information for the years 2008 to 2016. Active firms exclude companies that are defined alternatively as: under receivership, active but with no longer accounts on Orbis Bank Focus, bankrupted, dissolved, and in liquidation. The sample counts in total 6,134 firm-year observations. Using the ticker codes of the firms, we get from Datastream the monthly series of stock prices, which we use to compute the stock return skewness, as we describe it in the next section. In Table 1, we show the business specialization of our firms. The large majority are bank holdings and bank holding companies. ${ }^{\mathrm{b}}$ As can be seen, the bulk of assets is massively concentrated in finance group companies, namely largely diversified financial conglomerates.

Table 1. Business specialization of the United States sample firms (2008-2016).

\begin{tabular}{lrrrc}
\hline Business specialization & $N$ & $N(\%)$ & Total assets & Total assets (\%) \\
\hline Bank holdings \& Holding companies & 4840 & 85.63 & 34225248 & 16.53 \\
Commercial banks & 528 & 9.34 & 1106179 & 0.53 \\
Finance companies & 144 & 2.55 & 21930876 & 10.59 \\
Group finance companies & 8 & 0.14 & 96811224 & 46.76 \\
Investment banks & 24 & 0.42 & 746644 & 0.36 \\
Private banking/Asset management & 8 & 0.14 & 7299176 & 3.53 \\
Real Estate \& Mortgage banks & 20 & 0.35 & 10565261 & 5.10 \\
Savings banks & 48 & 0.85 & 252577 & 0.12 \\
Securities firms & 32 & 0.57 & 34082156 & 16.46 \\
Total & 5652 & 100 & 207019341 & 100 \\
\hline
\end{tabular}

\footnotetext{
${ }^{\mathrm{b}}$ Despite differences in the business specialization of the sample firms, in our discussion we refer interchangeably as "banks" or "financial firms."
} 


\subsection{Skewness-based measures}

We implement the following measures for stock return skewness:

\section{- Historical return-based skewness}

For each bank $j$ and year $t$, we calculate the skewness over the last 12 monthly stock returns $r$ as follows:

$$
\hat{\gamma}_{j, t}=\frac{\frac{1}{12} \sum_{t=1}^{12}\left(r_{j, t}-\bar{r}_{j}\right)^{3}}{\hat{\sigma}_{j}^{3}},
$$

where $\bar{r}$ and $\hat{\sigma}$ are the average return and the volatility over the period. The coefficient in (2.1) quantifies the skewness of the stock return realized over the year, and it can be regarded as a backward-looking measure of skewness, since it relies on the historical stock performance. Among others, Mitton \& Vorkink (2007), Mitton \& Vorkink (2010) and Boyer et al. (2010) show that (2.1) is inversely related to future expected stock returns and, as a consequence, that measuring skewness is important for the assessment of corporate value.

Nonetheless, according to Kraus \& Litzenberger (1976) only the coskewness of the stock return with the market portfolio (i.e. systemic skewness) matters for corporate valuation. Consistently, Harvey \& Siddique (2000) show that conditional coskewness explains the cross-sectional variation of future returns. To take this issue into consideration, in line with Mitton \& Vorkink (2007) we approximate the coskewness of bank $j$ with the coefficient $\hat{\gamma}(\mathrm{MV})_{j, t}$ estimated on the squared market excess return from the following regression:

$$
r_{j, t}-r_{f}=\alpha+\beta_{j}\left(r_{m, t}-r_{f}\right)+\hat{\gamma}(\mathrm{MV})_{j, t}\left(r_{m, t}-r_{f}\right)^{2}+\epsilon_{j, t},
$$

where $r_{m, t}$ is the market portfolio return at time $t$ and $r_{f}$ is the risk-free rate of return. ${ }^{\mathrm{c}}$ When $\hat{\gamma}(\mathrm{MV})$ takes positive values, it means that the stock and the market portfolio returns have extreme positive deviations at the same time.

\section{- Option-implied skewness}

Chang et al. (2013) and Conrad et al. (2013) show that the skewness of the optionimplied return distribution provides a better prediction for the future expected returns than the historical return-based skewness. Only a small group of our firms has stock options traded on stock exchanges. For this sub-sample, we calculate the option-implied skewness. We denote the risk-neutral density of $S_{\tau}$ at time $t$ by $\pi_{t, \tau}(\cdot)$. If a smooth strike $X$-continuum of expiry $\tau$ call option prices were observable at time $t, \mathrm{c}_{t, \tau}(X)$, then under absence of arbitrage, this density could be inferred in a model-free way. As shown first by Breeden \& Litzenberger (1978) we have

$$
\pi_{t, \tau}(X)=e^{r \tau} \frac{\partial^{2} \mathrm{c}_{t, \tau}(X)}{\partial X^{2}}
$$

\footnotetext{
${ }^{\mathrm{c}}$ For every time $t$, we take the values for $r_{m}$ and $r_{f}$ from the Fama/French data library that can be found at http://mba.tuck.dartmouth.edu/pages/faculty/ken.french/data_library.html.
} 
In reality, only a discrete set of strikes are available, which means that a considerable amount of smoothing and curve fitting is needed before Eq. (2.3) can be used to produce sensible numbers. Figlewski (2010, Sec. 2) provides a taxonomy of methods that are used for this purpose. We prefer to use the nonparametric clamped spline approach from Malz (2014), which is designed to avoid arbitrage opportunities that may arise for other nonparametric approaches. In line with all other techniques, the procedure requires data of reasonably good quality on the Black-Scholes implied volatility smile. The volatility smile changes over time and with different tenors, resulting in the so-called volatility surface $\sigma(t, X, \tau)$. The volatility surface translates into the market price of European call options as

$$
c(t, X, \tau)=\operatorname{BS}\left(S_{t}, X, \tau, \sigma(t, X, \tau), r_{t}, q_{t}\right),
$$

with $r_{t}$ and $q_{t}$ the continuously compounded interest rate and cash dividend yield of the underlying asset. We focus here on a single tenor $\tau$, rather than the entire surface. The technique can be summarized in three steps:

(1) Interpolate and extrapolate the volatility smile using a cubic spline function that is clumped at the endpoints. This corresponds to the assumption, that for very deep out-of-the-money options, the implied volatility is the same and equal to the furthest strikes in the input data. Clamping the interpolated smile ensures the call valuation function to be monotonic and convex in the exercise price, avoiding in this way violations of no-arbitrage restrictions.

(2) In order to calculate option prices, we use (2.4) by taking interpolated implied volatilities as arguments.

(3) Numerically differentiate the call valuation function with respect to the exercise price in order to approximate the density function $\pi_{t, \tau}(X)$. Therefore, the exercise-space is discretized with a step size $\Delta$,

$$
\pi_{t, \tau}(X) \approx e^{r_{t} \tau} \frac{1}{\Delta^{2}}[c(t, X+\Delta, \tau)+c(t, X-\Delta, \tau)-2 c(t, X, \tau)] .
$$

As $\Delta \rightarrow 0,(2.5)$ converges to the risk-neutral density.

Finally, we call as $\hat{\gamma}$ (opt) the skewness coefficient computed from the density in (2.5).

Table 2 gives descriptive statistics for the three skewness measures used in the analysis. On average, all quantities are quite low. The option-implied skewness is slightly higher than the return-based skewness. As we focus on the sub-sample of firms that have nonmissing values across the three measures, we notice that historical skewness becomes negative.

\subsection{Bank-specific characteristics}

The question is whether certain bank characteristics relate more significantly than others to stock return skewness. We now describe how we measure the most important corporate features, and show what effect these features have on skewness. 
Table 2. Descriptive statistics for measures of the skewness in the firm stock returns.

\begin{tabular}{lrrr}
\hline Variable & Mean & Std. dev. & $N$ \\
\hline Total return-based skewness $\hat{\gamma}$ & 0.117 & 0.867 & 5048 \\
Coskewness $\hat{\gamma}(\mathrm{MV})$ & -0.029 & 0.310 & 5668 \\
Option-implied skewness $\hat{\gamma}(\mathrm{opt})$ & 0.265 & 0.218 & 1120 \\
Sub-sample with not-missing values for $\hat{\gamma}, \hat{\gamma}(\mathrm{MV}), \hat{\gamma}(\mathrm{opt})$ & & & \\
Total return-based skewness $\hat{\gamma}$ & -0.165 & 0.630 & 1095 \\
Coskewness $\hat{\gamma}(\mathrm{MV})$ & -0.036 & 0.296 & 1095 \\
Option-implied skewness $\hat{\gamma}(\mathrm{opt})$ & 0.269 & 0.218 & 1095 \\
\hline
\end{tabular}

Note: $\hat{\gamma}$ is calculated as in $(2.1) .(\hat{\gamma})(\mathrm{MV})$ is calculated as in $(2.2) . \hat{\gamma}(\mathrm{opt})$ is calculated from the density in $(2.5)$.

Note that we include also aspects that are peculiar of financial firms. Table 3 reports descriptive statistics.

Following the standard practice within the empirical literature, we approximate bank size (SIZE) with the natural logarithm of total assets. ${ }^{\mathrm{d}}$ Increasing size raises also the complexity of banks, which would more likely experience frictions, as for example inefficiencies in the cash flow management or agency costs. Based on this hypothesis, we should observe that stocks return of large banks are less skewed than those of small banks.

For banking firms, the equity capital plays a more important role than for nonbanking firms, therefore we compute the capital-to-asset ratio to assess the leverage of our banks. EQUITY denotes the book value of equity divided by the book value of total assets. RB CAPITAL is the risk-based capital ratio computed in accordance to Basel II requirements, i.e. the sum of Tiers 1 and 2 capital over total risk-weighted assets. A low value for the capital ratio denotes high leverage, namely the bank is funded substantially with debt. If we assume that leverage makes agency conflicts more severe, to the point that it also encourages risk-taking, leverage should raise the probability of negative stock returns, i.e. reduce stock return skewness. Our firms are funded by more than $80 \%$ with debt, revealing that they are substantially levered (see Table 3).

One further aspect that clearly distinguishes banks from nonfinancial firms is the possibility to issue demandable debt. To take this aspect into consideration, the variable DEPOSITS gives the amount of customer deposits over total assets. Deposits constitute by far the largest source of debt for our firms, since deposits are funding around the $87 \%$ of assets. However, banks may issue "junior" debt-claims, which in the event of bankruptcy remain subordinated to deposits. This item is captured by the variable SUBDEBT, which normalizes the amount of subordinated debt by total assets. Inside the sample, the average share of subordinated debt is around $30 \%$ of assets. We argue that increasing subordinated debt would provide banks with an incentive to be more risk aggressive, whereas deposits would discipline

\footnotetext{
$\mathrm{d}$ Among the several papers where the bank size is approximated in the same way as we do in our analysis, see for example Demirgüç-Kunt \& Huizinga (2013).
} 
Table 3. Summary statistics.

\begin{tabular}{lccc}
\hline Variable & Mean & Std. dev. & $N$ \\
\hline Total assets $(000 \$)$ & 29,300 & 186,000 & 4109 \\
SIZE & 14.4 & 1.849 & 4109 \\
EQUITY & 0.130 & 0.132 & 4109 \\
RB CAPITAL & 0.161 & 0.086 & 3764 \\
DEPOSITS & 0.874 & 0.127 & 3687 \\
SUBDEBT & 0.293 & 0.754 & 3473 \\
LOANS & 0.691 & 0.174 & 4012 \\
ROA & 0.051 & 0.073 & 4109 \\
PE & 19.602 & 33.025 & 3049 \\
PB & 1.115 & 0.675 & 3442 \\
\hline
\end{tabular}

Notes: SIZE is the natural logarithm of total assets; EQUITY is the ratio of the book value of equity over the total assets; RB CAPITAL is the riskbased capital ratio computed as Tier 1 plus Tier 2 capital over risk-weighted assets; DEPOSITS is the ratio of total customer deposits over total assets; SUBDEBT is the ratio of total subordinated debt over total assets; LOANS is the ratio of total loans over total assets; ROA is the ratio of net income to total assets; PE is the market value per share over average earnings per share; $\mathrm{PB}$ is the market value per share over book value per share.

banks. The hypothesis that depositors can punish banks through withdrawals goes back to Calomiris \& Kahn (1991). The argument is that debt seniority disciplines banks' risk-taking, to the extent that banks increasing in deposits are encouraged to behave more prudently in order to avoid unexpected withdrawals. ${ }^{\text {e }}$ If subordinated debt encourages banks to undertake risky projects that have extreme outcomes, stock returns should become more asymmetric. If these projects are not successful, then we should observe that increasing subordinated debt leads to low skewness.

Our specifications include the loans-to-assets ratio (LOANS) to account for business diversification. A low value of LOANS denotes that the bank diversifies into nonlending activities. If nonlending activities entail severe risk, they will also be reflected into low stock return skewness. ${ }^{f}$ Notice that the loans-to-assets ratio is also inversely proportional to liquidity, because a high ratio tells that a large percentage of assets is tied up in loans, thereby making the bank less liquid.

Using the net income reported in the income statement, the return-on-assets (ROA) works as the indicator for the bank operating performance. We expect to find that profitable banks have positive skewness, as they deliver frequently high stock

e We refer to Martinez Peria \& Schmukler (2001) and the literature therein for empirical research that tries to disentangle the link between market discipline and deposits, under the existence of deposit insurance schemes.

${ }^{\mathrm{f}}$ For example, Laeven \& Levine (2007) use the loans-to-assets ratio to study the diversification discount attached to financial conglomerates. 
returns. Finally, following the insights in Del Viva et al. (2017), we include controls for the future growth options. Precisely, the variable PE is the ratio of market value per share over average earnings per share, while $\mathrm{PB}$ is the ratio of market value per share over book value per share. PE and PB are widely used by analysts to capture the existence of growth options, relying on the assumption that the market attributes a pricing premium for growth opportunities.

Table 4 reports the pairwise correlation among the variables of the analysis. The first three columns compute the correlation with the skewness measures. In particular, we notice that SIZE is negatively correlated to skewness, and the correlation coefficient is stronger in magnitude compared to the other bank characteristics.

We build a regression model that explains bank skewness as function of the bank characteristics outlined above. However, we acknowledge that including all bankspecific variables as predictors for a unique specification could create problems of multicollinearity. In fact, by looking at Table 4, we cannot state that the pairwise correlation is negligible in magnitude for all pairs. To tackle this issue, we estimate the following linear regression model using the selection method of backward stepwise selection (Wooldridge 2012), in order to explain the skewness of bank $j$ at time $t$ in relation to bank-specific features:

$$
\text { Skewness }_{j, t}=\alpha_{0}+\Theta \times \text { Bank features }_{j, t}+\tau_{t}+\epsilon_{j, t},
$$

where skewness is, alternatively, $\hat{\gamma}, \hat{\gamma}(\mathrm{MV})$, and $\hat{\gamma}(\mathrm{opt})$. $\Theta$ is the vector of coefficients for $j$-specific features, i.e. SIZE, EQUITY, RB CAPITAL, DEPOSITS, SUDDEBT, LOANS, ROA, PE, and PB. $\tau_{t}$ is a time dummy that captures time fixed effects, and $\epsilon_{j, t}$ is an error term. The method of backward stepwise selection is a semi-automated process of building a model by successively removing variables based on the $t$-statistics of the estimated coefficients, then potentially adding back variables if they later appear to be significant. The process is one such alternation between choosing the least significant variable to drop and then re-considering all dropped variables (except the most recently dropped) for re-introduction into the model. This means that two separate significance levels must be chosen for deleting variables from the model and for adding them back to the model. We fix the adding significance equal to $5 \%$, and the deletion significance equal to $10 \%$. The purpose of this procedure is to construct a model that mitigates potential problems of multicollinearity. The results from the estimate of (2.6) are reported inside Table $5 .^{\mathrm{g}}$

\footnotetext{
g We compute the variance inflated factors (VIFs) when all bank features are included together in the models estimated in Table 5 . In the regressions estimated in the first two columns, the VIFs are below four, while in the regression estimated in the third column, the VIFs are almost all below 5 (only ROA has a VIF of 5.41). Results are available upon request from the authors. Researchers often use the rule of thumb that a VIF equal to 10 indicates multicollinearity (Marquaridt 1970 and Mason et al. 2003). Therefore, based on our values, we can alleviate further the suspect that multicollinearity could contaminate the quality of the regression outcome.
} 
The Relationship Between Stock Return Skewness and Bank Features

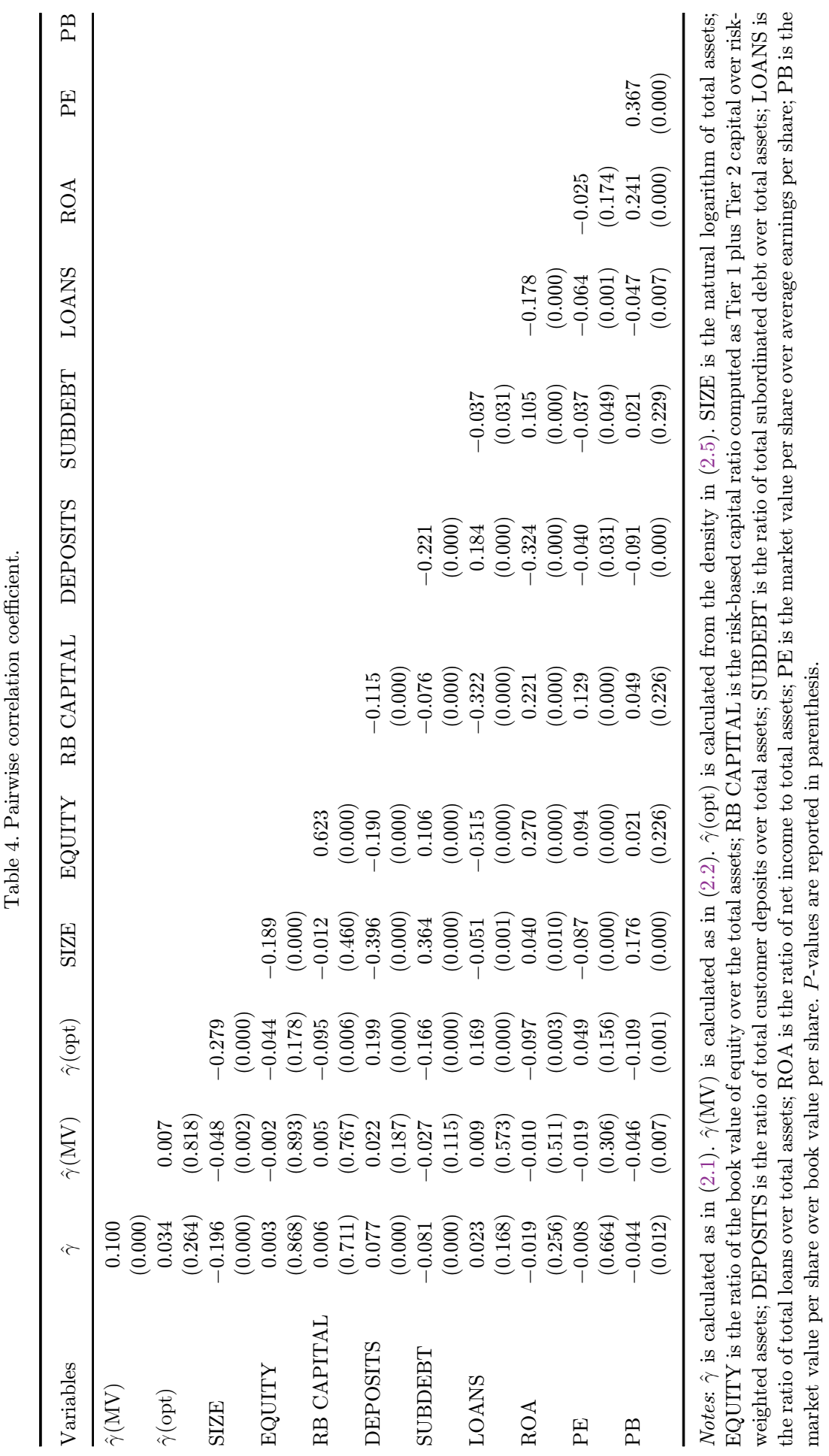


Table 5. The impact of bank-specific characteristics on skewness: Outcomes from stepwise regressions of stock return skewness.

\begin{tabular}{lccc}
\hline & $(2.1)$ & $(2.2)$ & $(2.3)$ \\
& $\hat{\gamma}$ & $\hat{\gamma}(\mathrm{MV})$ & $\hat{\gamma}(\mathrm{opt})$ \\
\hline SIZE & $-0.0901^{* * *}$ & $-0.00770^{*}$ & $-0.0400^{* * *}$ \\
& $(0.00834)$ & $(0.00329)$ & $(0.00540)$ \\
PB & $-0.0462^{*}$ & & $-0.0475^{*}$ \\
& $(0.0232)$ & & $(0.0190)$ \\
ROA & $-1.250^{*}$ & & \\
& $(0.508)$ & 0.0777 & \\
LOANS & & $(0.0447)$ & $-0.330^{* *}$ \\
RB CAPITAL & & & $(0.108)$ \\
& & & 721 \\
$N$ & 2,574 & 2,660 & 0.212 \\
\hline$R^{2}$ & 0.084 & 0.076 & \\
\hline
\end{tabular}

Notes: $\hat{\gamma}$ is calculated as in (2.1). $\hat{\gamma}(\mathrm{MV})$ is calculated as in (2.2). $\hat{\gamma}(\mathrm{opt})$ is calculated from the density in (2.5). The table shows outcomes from regressions using the selection method of backward stepwise selection. The variables considered for the final model are SIZE, EQUITY, RB CAPITAL, DEPOSITS, SUBDEBT, LOANS, ROA, PE, and PB. Variables are dropped from the model when they have significance lower than $10 \%$. Variables are reintroduced to the model when they have significance larger than $5 \%$. SIZE is the natural logarithm of total assets; EQUITY is the ratio of the book value of equity over the total assets; RB CAPITAL is the risk-based capital ratio computed as Tier 1 plus Tier 2 capital over risk-weighted assets; DEPOSITS is the ratio of total customer deposits over total assets; SUBDEBT is the ratio of total subordinated debt over total assets; LOANS is the ratio of total loans over total assets; ROA is the ratio of net income to total assets; PE is the market value per share over average earnings per share; $\mathrm{PB}$ is the market value per share over book value per share. Standard errors in parenthesis. ${ }^{*} p<0.05,{ }^{* *} p<0.01$ and ${ }^{* * *} p<0.001$.

\section{Empirical Evidence}

The most striking outcome in Table 5 is the negative coefficient of SIZE, which stays statistically significant across the three skewness measures. In contrast, the coefficients on the other variables are not equally robust. In other terms, bank size erodes skewness, whereas we cannot explain skewness with other bank features, as for example leverage or profitability. The size impact is stronger in the model for total skewness than for coskewness and options skewness. On the base of the coefficients estimated in Table 5, we can argue that, in economic terms, a $1 \%$ increase in bank size leads to an almost $17 \%$ reduction of skewness. ${ }^{\text {h }}$ If we rely on the hypothesis that skewness and future returns are interconnected, then we should conclude that the

\footnotetext{
${ }^{\mathrm{h}}$ To approximate the economic impact of the size effect, we compute the product of the coefficient estimated in Table 5 and the standard deviation of SIZE in Table 3.
} 
returns demanded from large banks are substantially higher than those from small banks. This finding would be in line with Albuquerque (2012), who comments that skewness is low and often negative inside large firms.

The negative sign of ROA suggests that the stock returns of highly profitable banks are less skewed than the stock returns of less profitable banks. The coefficient on LOANS turns out to be positive and significant at the $10 \%$ level. This suggests that low diversified banks, i.e. banks active in loan-making, have frequently positive stock performances. The negative sign on RB CAPITAL indicates that low amounts of regulatory capital diminish skewness. As the skewness of high growth banks is smaller than low growth banks, we get outcomes consistent with the findings of Del Viva et al. (2017). ${ }^{\text {i }}$

We notice that $R$-squared is higher inside the model for the forward-looking skewness implied by options rather than for the skewness of historical returns. However, we should bear in mind that the specification for option-based skewness is tested only on a subsample of the baseline data. However, we can state that, by means of size effects, we are able to explain in a better way the variability in the option-implied skewness rather than the historical return skewness.

\section{Systemically Important Financial Institutions (SIFIs)}

In order to dig deeper into the size effect documented in the previous section, we now investigate the stock return skewness of so-called "too-big-to-fail" institutions. ${ }^{j}$ To a certain extent, with SIZE we capture an implicit form of public guarantee, since we can arguably assume that, the larger is the bank, the more likely it will be that the government won't let it fail in order to prevent systemic spill-overs. ${ }^{\mathrm{k}}$

However, regulators provide a limited number of financial corporations with an explicit guarantee. In 1984, the United States Comptroller of the Currency in testimony before Congress argued that a group of 11 large banks were "too-big-to-fail," and that for those banks total deposit insurance would be provided. The goal of the regulators was to primarily avoid the failed firms that could draw a distress into other firms of the system. Despite this, the financial crisis 2008-2009 made the concern about the existence of big interconnected banks even stronger. This led the Financial Stability Board on November 4, 2011 to publish a list of SIFIs, which had to implement a set of measures to foster their solidity in front of future shocks. Our goal now is to study the skewness of the SIFIs included in the sample, by means of a dummy variable (SIFI) identifying the SIFIs from the United States: JPMorgan Chase, Citigroup, Goldman Sachs Group, Morgan Stanley, Bank of New York

\footnotetext{
${ }^{i}$ We use the market-to-book ratio to approximate growth options, whereas Del Viva et al. (2017) use the inverse quantity, i.e. the book-to-market ratio. Therefore, the sign estimated by Del Viva et al. (2017) is positive.

jWe refer to Kaufman (2014) for a discussion on too-big-to-fail resolution regimes.

${ }^{\mathrm{k}}$ In the paper of Ueda \& Di Mauro (2013), there are several factors which trigger the support of governments to SIFIs. The size of the company is one of these factors, which are though different across countries.
} 
Table 6. Sample split between SIFIs versus not SIFIs.

\begin{tabular}{lcccc}
\hline & NON-SIFI & SIFI & $t$-test & Wilcoxon's test statistic \\
\hline$\hat{\gamma}$ & 0.122 & -0.305 & $3.920^{* * *}$ & $4.749^{* * *}$ \\
$\hat{\gamma}(\mathrm{MV})$ & -0.028 & -0.103 & 1.911 & $2.489^{* *}$ \\
$\hat{\gamma}(\mathrm{opt})$ & 0.272 & 0.147 & $4.195^{* * *}$ & $4.379^{* * *}$ \\
Total assets & 9785655 & 1260000000 & $-96.566^{* * *}$ & $-13.727^{* * *}$ \\
SIZE & 14.300 & 20.676 & $-30.268^{* * *}$ & $-13.727^{* * *}$ \\
EQUITY & 0.131 & 0.098 & 2.015 & $4.029^{* * *}$ \\
RB CAPITAL & 0.161 & 0.171 & -0.930 & $-5.852^{* * *}$ \\
LOANS & 0.698 & 0.290 & $19.528^{* * *}$ & $8.563^{* * *}$ \\
DEPOSITS & 0.880 & 0.555 & $21.471^{* * *}$ & $11.911^{* * *}$ \\
SUBDEBT & 0.272 & 1.403 & $-12.124^{* * *}$ & $-15.239^{* * *}$ \\
PE & 19.726 & 13.430 & 1.462 & $3.461^{* * *}$ \\
PB & 1.118 & 0.946 & 2.023 & 1.424 \\
ROA & 0.051 & 0.044 & 0.775 & -1.283 \\
\hline
\end{tabular}

Notes: $\hat{\gamma}$ is calculated as in (2.1). $\hat{\gamma}(\mathrm{MV})$ is calculated as in (2.2). $\hat{\gamma}(\mathrm{opt})$ is calculated from the density in (2.5). The table shows outcomes from regressions using the selection method of backward stepwise selection. The variables considered for the final model are SIZE, EQUITY, RB CAPITAL, DEPOSITS, SUBDEBT, LOANS, ROA, PE, and PB. Variables are dropped from the model when they have significance lower than $10 \%$. Variables are re-introduced to the model when they have significance larger than $5 \%$. SIZE is the natural logarithm of total assets; EQUITY is the ratio of the book value of equity over the total assets; RB CAPITAL is the risk-based capital ratio computed as Tier 1 plus Tier 2 capital over risk-weighted assets; DEPOSITS is the ratio of total customer deposits over total assets; SUBDEBT is the ratio of total subordinated debt over total assets; LOANS is the ratio of total loans over total assets; ROA is the ratio of net income to total assets; $\mathrm{PE}$ is the market value per share over average earnings per share; PB is the market value per share over book value per share. Standard errors in parenthesis. ${ }^{*} p<0.05,{ }^{* *} p<0.01$ and ${ }^{* * *} p<0.001$.

Mellon Corporation, State Street Corporation, Wells Fargo, and Bank of America. This study is meaningful because SIFIs are firms of large systemic size, therefore we should observe an interesting interplay with stock return skewness.

Table 6 computes descriptive statistics for SIFIs in comparison to the rest of the sample. SIFIs concentrate the bulk of total assets and exhibit much lower skewness than the other firms. We note that the average historical skewness (both total skewness and coskewness) is lower than zero, showing that the stock returns of SIFIs have very long left-tails due to many negative outliers. ${ }^{\mathrm{m}}$ For the very large majority of the variables, the mean values are significantly different across the two subsamples according to the $t$-test as well as the Wilcoxon's test statistic.

Finally, we model skewness using SIFI as an instrument for SIZE. The assumption is that SIFI has an effect on skewness only through SIZE, but SIFI does not have

\footnotetext{
${ }^{1}$ The list published by the Financial Stability Board on November 4, 2011, indicates 29 firms worldwide that are considered SIFIs. Out of these firms, eight firms are headquartered in the United States, and are those banks that in our sample are identified by the variable SIFI. Bongini et al. (2015) and Abreu \& Gulamhussen (2013) analyze the reaction of financial markets to the publication of the SIFIs' list.

${ }^{m}$ There is evidence that too-big-to-fail policies entail the side effect of subsidizing risk-taking; see for example Boyd \& Gertler (1994), O'hara \& Shaw (1990), Flannery (2010) and Afonso et al. (2014).
} 
Table 7. Pairwise correlation with variable identifying SIFIs.

\begin{tabular}{lr}
\hline \multicolumn{1}{c}{ Correlation with SIFI $(N=944)$} \\
\hline SIZE & $0.4271^{* * *}$ \\
ROA & -0.0121 \\
EQUITY & $-0.0314^{*}$ \\
$\hat{\gamma}$ & $-0.0551^{* * *}$ \\
$\hat{\gamma}(\mathrm{MV})$ & -0.0254 \\
$\hat{\gamma}(\mathrm{opt})$ & $-0.1245^{* * *}$ \\
\hline Notes: $\hat{\gamma}$ is calculated as in $(2.1) . \hat{\gamma}(\mathrm{MV})$ is \\
calculated as in $(2.2) . \hat{\gamma}($ opt $)$ is calculated \\
from the density in $(2.5)$. SIFI takes value one \\
if the bank is one of the following institutions: \\
JPMorgan Chase, Citigroup, Goldman Sachs \\
Group, Morgan Stanley, Bank of New York \\
Mellon Corporation, State Street Corpora- \\
tion, Wells Fargo, and Bank of America. \\
SIZE is the natural logarithm of total assets; \\
EQUITY is the ratio of the book value of \\
equity over the total assets. Standard errors \\
in parentheses. $* p<0.05, * * p<0.01$ and \\
$* * * p<0.001$.
\end{tabular}

a direct effect on skewness. In Table 7, the correlation between the two variables is above 0.40 , therefore we argue that SIFI could be a potential good instrument for SIZE.

We conduct an instrumental variable estimation in two steps. In the first step (4.1), we regress SIZE on the instrument SIFI, plus controls. In the second step (4.2), we use the values predicted from the first step regression to explain the skewness measures, in accordance to the following notation:

$$
\begin{aligned}
& \operatorname{SIZE}_{j, t}=\operatorname{SIFI}_{j, t}+\mathrm{ROA}_{j, t}+\mathrm{EQUITY}_{j, t}+v_{t}, \\
& \text { Skewness }_{j, t}=\mathrm{SIZE}_{j, t}+\mathrm{ROA}_{j, t}+\mathrm{EQUITY}_{j, t}+\tau_{t} \\
& \text { Skewness }_{j, t}=\left\{\hat{\gamma}_{j, t}, \hat{\gamma}(\mathrm{MV})_{j, t}, \hat{\gamma}(\mathrm{opt})_{j, t}\right\},
\end{aligned}
$$

where $\mathrm{SIZE}_{j, t}$ denotes bank size as predicted from the too-big-too-fail status, plus profitability and capital, while $\tau_{t}$ and $v_{t}$ are time fixed effects. Table 8 illustrates the outcomes from (4.2). The pattern is similar to Table 5, since we obtain a negative and significant sign on the instrumented SIZE. The test for endogeneity suggests that SIZE can be regarded as endogenous only in the model for the historical return based skewness, while it would be exogenous for the other two skewness measures. ${ }^{n}$

$\mathrm{n}$ The endogeneity test is defined as the difference of two Sargan-Hansen statistics: one for the equation where the suspect regressor is treated as endogenous, and one for the equation with where the suspect regressors is treated as exogenous. Also like the $C$-statistic, the estimated covariance matrix used guarantees a nonnegative test statistic. Under conditional homoskedasticity, this endogeneity test statistic is numerically equal to a Hausman test statistic; see Hayashi (2000, pp. 233-234). 
Table 8. Regressions for bank skewness: SIZE instrumented by SIFI.

\begin{tabular}{lccc}
\hline & $(2.1)$ & $(2.2)$ & $(2.3)$ \\
& $\hat{\gamma}$ & $\hat{\gamma}(\mathrm{MV})$ & $\hat{\gamma}(\mathrm{opt})$ \\
\hline SIZE (instrumented) & $-0.0637^{* * *}$ & $-0.0120^{*}$ & $-0.0282^{* * *}$ \\
& $(0.00821)$ & $(0.00515)$ & $(0.00689)$ \\
ROA & -0.141 & -0.0171 & -0.208 \\
& $(0.201)$ & $(0.0637)$ & $(0.152)$ \\
EQUITY & -0.179 & -0.0154 & -0.0595 \\
& $(0.125)$ & $(0.0494)$ & $(0.0851)$ \\
$N$ & 3,710 & 3,967 & 960 \\
$R^{2}$ & 0.075 & 0.059 & 0.151 \\
Endogeneity test $\left(\chi^{2}\right)$ & $5.117^{* *}$ & 0.756 & 0.721 \\
Kleibergen-Paap statistic $\left(\chi^{2}\right)$ & $8.149^{* *}$ & $8.127^{* *}$ & $8.881^{* *}$ \\
\hline
\end{tabular}

Notes: $\hat{\gamma}$ is calculated as in (2.1). $\hat{\gamma}(\mathrm{MV})$ is calculated as in (2.2). $\hat{\gamma}$ (opt) is calculated from the density in (2.5). SIFI takes value one if the bank is one of the following institutions: JPMorgan Chase, Citigroup, Goldman Sachs Group, Morgan Stanley, Bank of New York Mellon Corporation, State Street Corporation, Wells Fargo, and Bank of America. SIZE is the natural logarithm of total assets; EQUITY is the ratio of the book value of equity over the total assets. Standard errors in parentheses. ${ }^{*} p<0.05,{ }^{* *} p<0.01$ and ${ }^{* * *} p<0.001$.

For all three regressions, the test based on the Kleibergen-Paap statistic rejects the null hypothesis that the instrument SIFI has insufficient explanatory power to predict SIZE in the model for identification of the parameter, i.e. SIZE would not be underidentified.

\section{Conclusions}

This paper shows that bank size, measured in terms of bank total assets, is negatively related to stock return skewness. Thus, large banks are more likely to have severe losses. If we rely on the argument that left-tailed returns imply higher expected returns, then our results indicate that expected bank returns are increasing in bank size. This claim is of primary importance for the valuation of corporate equity. In fact, discounted cash flow methodologies require to discount the future cash flows at an appropriate discount rate that reflects the expected equity performance. ${ }^{\circ}$ Therefore, the outcomes ultimately suggest that size could reduce the ex-ante pricing of bank equity.

\section{References}

J. F. Abreu \& M. A. Gulamhussen (2013) The stock market reaction to the public announcement of a supranational list of too-big-to-fail banks during the financial crisis, Journal of International Financial Markets, Institutions $\&$ Money 25 (1), 49-72.

o The most important theories for corporate valuation refer to the Sharpe-Lintner-Black Capital Asset Pricing Model (Sharpe 1964, Lintner 1965 and Jensen et al. 1972), the asset pricing theory of Ross (1976), and the multi-factor approach of Fama \& French (1993). 
G. Afonso, J. Santos \& J. Traina (2014) Do "Too-Big-to-Fail" banks take on more risk? Federal Reserve Bank of New York Economic Policy Review 20 (2), 1-18.

R. Albuquerque (2012) Skewness in stock returns: Reconciling the evidence on firm versus aggregate returns, The Review of Financial Studies 25 (5), 1630-1673.

F. D. Arditti (1967) Risk and the required return on equity, The Journal of Finance 22 (1), 19-36.

T. G. Bali, J. Hu \& S. Murray (2017) Option implied volatility, skewness, and kurtosis and the cross-section of expected stock returns, Georgetown McDonough School of Business Research Paper.

T. G. Bali \& S. Murray (2013) Does risk-neutral skewness predict the cross-section of equity option portfolio returns? Journal of Financial and Quantitative Analysis 48 (4), $1145-1171$.

N. Barberis \& M. Huang (2008) Stocks as lotteries: The implications of probability weighting for security prices, American Economic Review 98 (5), 2066-2100.

F. Black (1976) Studies of stock price volatility changes, Proceedings of the 1976 Business Meeting of the Business and Economic Statistics Section, American Statistical Association, pp. 177-181.

P. Bongini, L. Nieri \& M. Pelagatti (2015) The importance of being systemically important financial institutions, Journal of Banking and Finance 50, 562-574.

J. H. Boyd \& M. Gertler (1994) The role of large banks in the recent us banking crisis, Federal Reserve Bank of Minneapolis. Quarterly Review-Federal Reserve Bank of Minneapolis 18 (1), 2.

B. Boyer, T. Mitton \& K. Vorkink (2010) Expected idiosyncratic skewness, Review of Financial Studies 23 (1), 170-202.

D. T. Breeden \& R. Litzenberger (1978) Prices of state-contingent claims implicit in option prices, Journal of Business 51 (4), 621-651.

M. K. Brunnermeier, C. Gollier \& J. A. Parker (2007) Optimal beliefs, asset prices, and the preference for skewed returns, American Economic Review 97 (2), 159-165.

M. K. Brunnermeier \& J. A. Parker (2005) Optimal expectations, American Economic Review 95 (4), 1092-1118.

C. W. Calomiris \& C. M. Kahn (1991) The role of demandable debt in structuring optimal banking arrangements, The American Economic Review 81 (3), 497-513.

J. Y. Campbell \& L. Hentschel (1992) No news is good news: An asymmetric model of changing volatility in stock returns, Journal of Financial Economics 31 (3), 281-318.

B. Y. Chang, P. Christoffersen \& K. Jacobs (2013) Market skewness risk and the cross section of stock returns, Journal of Financial Economics 107 (1), 46-68.

J. Chen, H. Hong \& J. C. Stein (2001) Forecasting crashes: Trading volume, past returns, and conditional skewness in stock prices, Journal of Financial Economics 61 (3), $345-381$.

A. A. Christie (1982) The stochastic behavior of common stock variances: Value, leverage and interest rate effects, Journal of Financial Economics 10 (4), 407-432.

J. Conrad, R. F. Dittmar \& E. Ghysels (2013) Ex-ante skewness and expected stock returns, The Journal of Finance 68 (1), 85-124.

L. Del Viva, E. Kasanen \& L. Trigeorgis (2017) Real options, idiosyncratic skewness, and diversification, Journal of Financial and Quantitative Analysis 52 (1), 215-241.

A. Demirgüç-Kunt \& H. Huizinga (2013) Are banks too big to fail or too big to save? International evidence from equity prices and CDS spreads, Journal of Banking and Finance 37 (3), 875-894.

D. W. Diamond \& R. E. Verrecchia (1987) Constraints on short-selling and asset price adjustment to private information, Journal of Financial Economics 18 (2), 277-311. 
A. Ekholm \& D. Pasternack (2005) The negative news threshold - An explanation for negative skewness in stock returns, The European Journal of Finance 11 (6), 511-529.

L. G. Epstein \& M. Schneider (2008) Ambiguity, information quality, and asset pricing, The Journal of Finance 63 (1), 197-228.

E. F. Fama \& K. R. French (1993) Common risk factors in the returns on stocks and bonds, Journal of Financial Economics 33 (1), 3-56.

S. Figlewski (2010) Estimating the implied risk neutral density for the U.S. market portfolio. In: Volatility and Time Series Econometrics: Essays in Honor of Robert F. Engle. Oxford University Press.

M. J. Flannery (2010) What to do about TBTF, In: Federal Reserve Bank of Atlanta 2010 Financial Markets Conference - Up From the Ashes: The Financial System After the Crisis, Vol. 12, pp. 1-30.

K. R. French, G. W. Schwert \& R. F. Stambaugh (1987) Expected stock returns and volatility, Journal of Financial Economics 19 (1), 3-29.

C. R. Harvey \& A. Siddique (2000) Conditional skewness in asset pricing tests, The Journal of Finance 55 (3), 1263-1295.

F. Hayashi (2000) Econometrics, Princeton University Press.

H. Hong \& J. C. Stein (2003) Differences of opinion, short-sales constraints, and market crashes, Review of Financial Studies 16 (2), 487-525.

M. C. Jensen, F. Black \& M. S. Scholes (1972) The capital asset pricing model: Some empirical tests, Studies in the Theory of Capital Markets. Praeger Publishers Inc.

Y. Jia \& S. Yan (2016) What does skewness of firm fundamentals tell us about firm growth, profitability, and stock returns, Oklahoma State University Working Paper.

G. G. Kaufman (2014) Too big to fail in banking: What does it mean? Journal of Financial Stability 13, 214-223.

A. Kraus \& R. H. Litzenberger (1976) Skewness preference and the valuation of risk assets, The Journal of Finance 31 (4), 1085-1100.

L. Laeven \& R. Levine (2007) Is there a diversification discount in financial conglomerates? Journal of Financial Economics 85 (2), 331-367.

J. Lintner (1965) The valuation of risk assets and the selection of risky investments in stock portfolios and capital budgets, The Review of Economics and Statistics 47 (1), 13-37.

A. M. Malz (2014) A simple and reliable way to compute option-based risk-neutral distributions, Federal Reserve Bank of New York, Staff Report No. 67\%.

D. W. Marquaridt (1970) Generalized inverses, ridge regression, biased linear estimation, and nonlinear estimation, Technometrics 12 (3), 591-612.

M. S. Martinez Peria \& S. L. Schmukler (2001) Do depositors punish banks for bad behavior? market discipline, deposit insurance, and banking crises, The Journal of Finance 56 (3), $1029-1051$.

R. L. Mason, R. F. Gunst \& J. L. Hess (2003) Statistical Design and Analysis of Experiments: With Applications to Engineering and Science. John Wiley \& Sons.

T. Mitton \& K. Vorkink (2007) Equilibrium underdiversification and the preference for skewness, Review of Financial Studies 20 (4), 1255-1288.

T. Mitton \& K. Vorkink (2010) Why do firms with diversification discounts have higher expected returns? Journal of Financial and Quantitative Analysis 45 (6), 1367-1390.

M. O'hara \& W. Shaw (1990) Deposit insurance and wealth effects: The value of being 'toobig-to-fail', The Journal of Finance 45 (5), 1587-1600.

R. S. Pindyck et al. (1984) Risk, inflation, and the stock market, American Economic Review 74 (3), 335-351.

S. A. Ross (1976) The arbitrage theory of capital asset pricing, Journal of Economic Theory 13, 341-360. 
R. C. Scott \& P. A. Horvath (1980) On the direction of performance for moments of higher order than the variance, The Journal of Finance 35 (4), 915-919.

W. F. Sharpe (1964) Capital asset prices: A theory of market equilibrium under conditions of risk, The Journal of Finance 19 (3), 425-442.

P. S. Stilger, A. Kostakis \& S.-H. Poon (2016) What does risk-neutral skewness tell us about future stock returns? Management Science 63 (6), 1814-1834.

K. Ueda \& B. W. Di Mauro (2013) Quantifying structural subsidy values for systemically important financial institutions, Journal of Banking and Finance 37 (10), 3830-3842.

J. M. Wooldridge (2012) Introductory Econometrics: A Modern Approach. South-Western Cengage Learning.

J. Xu (2007) Price convexity and skewness, The Journal of Finance 62 (5), 2521-2552. 